\title{
Suggested View for the Open University Center in New Valley Governorate
}

\author{
Magdy Abdel Raman Abdallah
}

\author{
Foundations of Education Department, Faculty of Education, New Valley - Assist University
}

\author{
Doi:10.5901/mjss.2014.v5n23p1113
}

\begin{abstract}
The current study aims at desiging a suggested model for Open university education center in New Valley by identifying the philosophy of Open university education in Egypt, the role of Open university education in developing the society of New Valley, and the reality of Open university education in New Valley. In order to achieve this aim: The study's problem is manifested in the following questions: What is the philosophy of Open university education in Egypt? What is the role of Open university education in developing the society of New Valley? What is the reality of Open university education in New Valley? What is the suggested model for Open university education center in New Valley? To answer the questions above, a descriptive analytical method in the study's procedures, and Four instruments were used: Philosophy of Open Education, The role of Open university education in developing New Valley, The reality of Open university education, Suggested View for the Open University Center in New Valley governorate. The outcomes of the study were developeng a proposed model for University Education Center Open New Valley governorate. which will contribute to Encouraging students to move and live in the locations of developmental projects and continuing their Open Education as long as there are learning media and modern technology. The study recommended : Supporting the suggested center by Assiut University council and providing it with the necessary resources.; The coordination between Assiut University and New Valley governorate to form a committee that specifies the needed specializations and programs. ; Preparing activities and programs to motivate students to join the suggested center.
\end{abstract}

\section{Introduction}

Our century seems to be an age to witness a lot of political, social and technological changes. Similar changes have been also undergone by previous centuries. But globalization appears to push these changes to expand and continue with an increasing efficiency. These developments and changes have significant impacts on life's, demands and needs of people, while affecting styles and approach of meeting those needs.

In the light of globalization and its implications, faster growth of the economy of a country human capital should be available along with physical capital. That is why, improving and expanding education are essential ingredients of any national development policy.

However, developing countries fail to offer education to all sections of people in society through conventional oncampus system of education due to lack of infrastructural facilities and also some constraints embodied in it.

Egypt is one of the third world countries, who suffered backwardness, which creates lots of chaos in the social, political and economic environment. To cope with the present economic backwardness and to avoid prospective fears of severe socio-economic crisis, it needs a big push toward better socio-economic performance of the country, which is not possible without improving the human capital position of the country. (Mustafa, 2011)

As a result Egypt has become in more need of education owing to an information explosion. In turn it has led to the development of new educational technologies and methods to have caused change in education by degree. Traditional educational institutions fall behind the increasing education demand. Resulting education deficit has been gradually growing day by day. (Saied and Seraj, 2006)

Today, we are experiencing "information age", in which the role of universities at social and economic level has gained considerable importance. Therefore, it is clear that economic, scientific and technological developments require the initiation of effective restructuring processes in higher education systems.

Moreover, the demand for higher education is also increasing during information age, which makes it necessary for higher education systems to develop their own accountable and transparent processes.

Many significant changes occur in the field of higher education institutions Egyptian just like in other higher education institutions. Increasing the quality of higher education, ensuring the transparency and comparability of sustainable education systems at international level and the attempts to make such systems more practical and easily 
adaptable are the significant dynamics of such changes.(Khalion, 1998)

As the inevitable effects of all these developments and changes and challenges, the higher education systems all over the world are now going through various transformation processes. Many countries have already initiated regional collaboration units in order to compare their own higher education systems with others and to find common solutions.

This situation has urged Egypt to search for alternative education to traditional one and the concept of "Distance Education" is an output of this search. The main driving force behind these developments is the effort of meeting educational demands of people as a result of rise in numbers of student, education demand of different student populations, former students, rise in jobs and working bringing with it a lifelong learning. (Kamil and Oznur, 2012)

The Open University Education has a campanied role to the roles of higher education instiutions in qualifing and preparing human resources for completing plans of development.( Jacob, 2004)

In addition, this type of education has become a necessary choice not only for the developed countries but also the developing countries that intend to access education to all citizens inorder to prepare professional and technicians. (Nashwan, 2004)

Egypt can be considered one of these countries that attempted to apply Open University Education through establishing centers for open education in universities such as Alexandia, Cairo, Assiut, ain shams ..... ets. This requires the interest of conducting evaluation, development and improvement comprehensively and continously as there are many reasons necessitate that.

Students enrolled in Open Education in Egyptian universities represent a great section of the society.Egyptian universities attempt to attract them as a response to the increasing social demand. This led to the random acceptance of students without any specefic criteria except the low score of high school which may be $50 \%$ of the total score, the absence of the criterion of the score for the graduates of technical high schools, and replacing this criterion with another one which is passing 5 years after being graduated form technical high schools.

As a result of the strong belief of the state in the importance of Open Education, two brances of Open Education of Cairo University and Assiut University were established in New Valley in 2007/2008; the first is subordinated to the Open university education center of Cairo University and the other is subordinated to Assiut University.

Due to the university's interest in the quantitive aspect of the process of students admission to open education, "the follower of students' affairs and their condition does not find it difficult to monitor the reality which suffers from many of the problems that its effects which is reflected on students themselves and the society as well." (Fathy and Mohammed, 2010)

It also should be noted that the two braches of Open Education in New Valley are not immune from administrative and academic problems faced by their colleagues in other universities; moreover, they suffer more from other problems related to the far geographical location of the governerate which necessitates a scientific view to develop this type of learning and soloving its current problems consiously and unconvetionally.

\section{Problem of the Current Study}

Although the officials of Open Education of Assiut and Cairo universities and those in charge of the educational system Open New Valley governorate are aware that this type of education has a special philosophy of educational, and also has its objectives and mechanisms, which distinguishes it from formal university education, but the fast and unplanned application at the outset did not offer enough time to complete base of potential and ingredients that can respond effectively to the application of the educational system and its objectives.

In addition, the components and specialities of Open Education in New Valley have been implemented randomly without any study of the actual labour market's needs or even the wishes of the students in the governrate where Assiut University estabilshed two faculties of commerce and law and ignored that New Valley is basiclly an agriculture governerate. Moreover, specialties open education programs in the New Valley has been implemented in a random and not based on studies of the labor market needs of actual maintain or even to the wishes of students. (Elakaad, 2001)

And despite the fact that the main center of the Open Learning at the University of Cairo has addressed this problem, the opening of the College of Agriculture, however, put an obstacle prevented larg numbers of students to join the college. This aobstacle is represented in the travel of students to cairo to receive practical training, and which lasts for months, which in turn increases some additional expenses student can not bear.

Reviewing the reality of the Open Education in the Egyptian universities reveals that the problems of the open univrsity eductaion in far governrate like New Valley are lack of clear philosophy, application without planning, increasing sepcialities accoring to responsible authorities, and ignoring desires of students and work markets' needs.(New Valley governorate, 2012) 
Open university education insititutes in New Valley as well as other educational insititution have many problems that must be detected and solved to achive the targeted aims. So, the researcher- provoked by the belief that development and inmpovement can not be achieved without identifying the reality- investigated the practices of the Open unversity education in New Valley to participate in desiging plans and programs to develop this type of education.

\section{Questions of the Study}

1- What is the philosophy of Open university education in Egypt?

2- What is the role of Open university education in developing the society of New Valley?

3- What is the reality of Open university education in New Valley?

4- What is the suggested model for Open university education center in New Valley?

\section{Aims of the Study}

The current study aims at desiging a suggested model of Open university education center in New Valley by identifying:

1- the philosophy of Open university education in Egypt.

2- the role of Open university education in developing the society of New Valley.

3- the reality of Open university education in New Valley.

\section{Significance of the Study}

1- The current study contributes to the detection of the strengths and weaknesses in the open education in Egyptian universities, which in turn offers decision makers a scientific databese that help make the best decisions to raise the quality and development.

2- The current study gives the responsible for the Open education system in the New Valley an illustrative vision to avoid weaknesses in the structure of this system which coincided with related studies that evaluated the reality in Egypt.

\section{Methodology of the Study}

The current study adoptes the Descriptive approachto describe and analyze the identity and philosophy of open education in Egypt and identifying its through theoritical analysis of related literatre and previous studies.

\section{Terms of the Study}

\subsection{Open Education}

Open Education is defined as an Education method supplying an opportunity of education to individuals who were not able to study in formal education institutions, because of age, illness and geographical distance or individuals who lost that opportunity. This education is offered through using various materials such as pressed, visual,auditoria, and electronic materials.(Demiray ,1999)

The researcher defines Open Education as "the educational system that offers educational opportunities for all individuals of any age among high school graduates or technical high school graduates who missed their chance of education. They join open education according to their desires, needs and abilities by using modern and untraditional techniques and methods in the time they want".

\subsection{Open University Education Center}

It is an educational and cultural center. It represents an avenue of the university to the society through which the university offers public education with no limits of age, time and level, and suits the nature, needs, ambitions and development of professions of the people. 


\subsection{Review of related literature}

There were many studies that dealt with Open Education from the begining; some of these studies attempted to identify the challenges and problems of Open Education but they differed in the target audience of the study like (Shaheed 2005), (Abd Attalla Hamaiel, Magid Attalla Hamaiel 2006), (Mahmoud AboSamra et al 2006). The analysis of these studies revealed that they all agree in identifyi ng the obstacles of Open Education which were represented in the unsuitability of courses to students' attitudes and abilities, lack of knowledge of university discipline, and lack of care of students' inquires and problems.

Some studies attempted to identify the reality of Open Education in Egypt in order to evaluate this reality like (Yakoub, 2001), (Abd Elrahman 2000), (Alazab, 2001; Metwally, 2004and Elsaidi, 2005). The analysis of their results revealed lack of philosophy of Open Education and unplanned implementation of Open Education program. They all recommended increasing the specialties in open education centers to suit labour market and students' needs.

The current study benefited these results in identifying the philosophy of Open Education and specifying the obstacles and problems which corresponded to all Open Education programs in Egypt.

The current study also coincides with these studies in evaluating the present reality of Open Education and using the descriptive approach and differs from these studies in using the theoretical analysis rather than practical one.

\section{Theoretical Framework for the Study}

\subsection{Philosophy of Open Education}

Open Education is thought to be an effective way of educating people of all sections in society. The delivery system in distance education is different from that in the conventional on-campus teaching.

However, Open Education is considered as close substitute for the conventional on-campus teaching keeping in mind the premises that different types of media (print, audio, video, telephone, computer based communication system, etc.) are synchronized in the delivery process in Open and distance education system. Of course, in this age of information super highway, nobody can challenge the possibility that effective and quality education can be offered through different types of modern media - without any real classroom. Real classroom can be substituted by virtual classroom environment. (Sadia and Mostafa, 2002)

It is necessary to note that Open Education in terms of its most recent developments cannot be separated from the development of Open systems and the history of Open source, Open access, open archiving, and Open publishing. Education has always been dependent to some degree on changing information and communication technologies from the abacus and stone tablet to the blackboard and computer.

The more critical questions is to understand how these new technologies, and especially Web 2.0 platforms and protocols, promote a ubiquitous learning that collapses spaces between school and home, work and school, work and personal interest, teacher and student and so on, transforming formal education and the market and creating new forms of social production that are essential to the knowledge economy. (Michael and Rodrigo, 2008)

\subsection{Concept of Open Education}

In the awake of Open Education, due to less attention to this system not many theories have been developed regarding Open Education, which interfered with the visibility of its identity. However, a set of reliable Open learning theories have only began to recently emerge. Different theories explain Open Education in different ways.

Proposes an initial classification for some of the Open Education theories as follows: (Keegan, 1986)

1. Theories of independence : Open Education is the independence of the students

2. Theories of industrialization of teaching : Open Education is the industrialized form of teaching and learning .

3. Theories of interaction and communication: Open teaching supports student motivation, promote learning pleasure, creates feelings of rapport between learner and the distance education institution.

Open Education is the system of education where students learn by themselves in the absence of classrooms. Teachers are separated from the students - students do not get any personal touch of the teacher. A wide variety of media are used to serve numerous educational programs to students.

(Wikipedia, 2014) is known Open Education as a collective term to describe institutional practices and programmatic initiatives that broaden access to the learning and training traditionally offered through formal education systems. The qualifier "Open" of Open Education refers to the elimination of barriers that can preclude both opportunities 
and recognition for participation in institution-based learning.

The term Open learning describes policies and practices that permit entry to learning with as few barriers as possible. For example, when the Open University in the UK was created in 1969, it based its claim to be Open by abolishing all academic prerequisites for entry. Potential learners did not have to show any evidence of having been to school or passed any examinations. Once they start, they have to work hard to pass courses and continue - but there are no barriers to starting. (Christelle, 2013)

It also looks at the Open Education that is the system of education where students learn by themselves in the absence of classrooms. Teachers are separated from the students - students do not get any personal touch of the teacher. Wide varieties of media are used to serve numerous educational programs to students.

According to (Simonson and et al., 2000)" the term distance education have been applied to a tremendous variety of programs serving numerous audiences via a wide variety of media".

American Council on Education (ACE) defines distance education as 'a system and a process of connecting learners with distributed learning resources. (Chute and et al., , 1999) .

On the other hand Open Education learners always enjoy flexibility in terms of choosing the place and time of study. However, the degree of flexibility the students able to enjoy depends on the availability of the media and learner's access to them. Based on the availability of technology, flexibility in Open Education system varies worldwide. However, it is true that Open Education must have at least some flexibility in compared to most inflexible traditional on-campus education system.

The emergence of new information and communication technologies offered the right tools to reach out to people irrespective of their location and specific circumstance. Time and space ceased to be barriers to education. This unprecedented demand for growth has led to the evolution of new institutional structures, flexible and innovative teaching and learning styles that have transformed the traditional approaches to education. The role played by Open Education is a key element in this metamorphosis.

\subsection{Conceptual underpinnings of Open Education}

In light of the above it is clear The conceptual bases of Open Education are: (Alkan, 1996)

1. to create new resources

2. to provide unity between occupation and education

3. to democratize the learning process

4. to supply lifelong learning training

5. individualism in education

6. to benefit from existing training institutions effectively

7. using technology in education effectively

8. inclining the needs of individuals, society, and technology

9. to discourse to the masses;

10. to provide unity of individual and massive education

11. in addition, it is sequenced that training demand and financial recourses are stabilized.

\subsection{The difference between Open Education and distance education}

Open Education, is a relative term but it does express the ambition of an institution to remove those barriers to learning that are particularly restrictive in its own environment.

While distance education refers to the methodology by which the learners are reached, open learning refers to the philosophy underlining Open entry and access to learning opportunities. Though the two are conceptually distinct, distance education and Open Education are often complementary. Opening up learning without introducing some elements of distance education is not always possible and introducing distance education inevitably opens up learning in new ways for many people.

Hilary Perraton has pointed out that the term distance education captures the economic imperative of gaining benefits of scale, low-cost, and consistent quality, whereas Open learning evokes the political imperative of widening access. ( Kanwar and Daniel, 2010 ) 


\subsection{The objectives of the Open Education}

One of the main objectives of Open universities is to educate everyone. For various reasons, some people do not complete school, as they should. They may experience the loss of a parent at a young age and be forced to leave school to help with the family. On the other hand, they may have dropped out of high school. With a typical university, the student must find a way to complete her schooling before admission. An Open University allows students such as these to continue with a college-level education without going back to finish lower grades first. It also allows students who would not be accepted to traditional universities the chance to further their education.

Some people cannot afford to move away for school and may not live close enough to attend a university on the local level. Open universities offer their courses online through distance learning. This allows them to reach a wider range of people who may not otherwise be able to attend college. In addition to the location factor, online classes allow students to complete those classes whenever it is convenient for them. Students can easily work all day and complete coursework in the evenings.(Lockwood, 1995)

\subsection{Principles of Open Education}

Open Education is an approach to education that seeks to remove all unnecessary barriers to learning, while aiming to provide students with a reasonable chance of success in an education and training system centered on their specific needs and located in multiple arenas of learning. It incorporates several key principles:( Neil B., 2011)

1. Learning opportunity should be lifelong and should encompass both education and training.

2. The learning process should centre on the learners, build on their experience and encourage independent and critical thinking;

3. Learning provision should be flexible so that learners can increasingly choose, where, when, what and how they learn, as well as the pace at which they will learn.

4. Prior learning, prior experience and demonstrated competencies should be recognized so that learners are not unnecessarily barred from educational opportunities by lack of appropriate qualifications.

5. Learners should be able to accumulate credits from different learning contexts;

6. Providers should create the conditions for a fair chance of learner success.

\subsection{The role of Open university education in developing New Valley}

The Open university education represents a qualitative shift in the society of New Valley as it was deprived untill recently from higher education institutions. Providing this type of education has helped a lot of youn g people to continue their university study especially those who were prevented by their professional and practical and living circumstances of enrollment at the university.

Because the community of New Valley is a farming community, the open university education provides the opportunity for workers in the agricultural fields to develop their abilities and update their information without having to study full-time or leave their job. It also allows the open university education and, in particular, of the College of Agriculture to provide the student with the knowledge and information

And experiences that qualify him to practice the profession of agriculture and management of agricultural projects in the areas of agricultural expansion to governrate. (Suez Canal University)

The role of Open university education in developing the society of New Valley can be summarized as follows:

1- Preparing the necessary human recources to achieve comprhensive development plans in the governrate'(Abd Elmotelib, 2006), and some develoment projects like Toushka, Darb Arbain, Shark Owainat ..... ets, and other projects that aim to make a quantum leap to Egypt, especially in the agricultural field.

2- Offering opportunity for the owners of the various disciplines among those who obtained advanced degrees to study and absorb knowledge in other disciplines by attending the Open University and the consequent deployment of thought and culture, and then make a real development in many areas ( Bedewi,2008)

3- Opening new specializations that fit the developmental nature of the New Valley Governorate, such as the College of Agriculture.

4- Linking open education to New Valley environment in away that addresses environmetal issues and contributes to the acheivement of development.

5- Participating in solving the problem of illiteracy and education of adults.

6- Consolidating values and developmental attitudes in the society of New alley. 
7- Offering professional growth of all employees in different fields of work.

8- Contribute to the education of women and encourage them to do so.

9- Creating the Opportunity of social mobility, where the division of society into classes is not consistent with democracy and development.

10- Encouraging students to move and live in the locations of developmental projects and complete their Open Education as long as educational means and modern technology of learning will be available to students in these places

\subsection{The reality of Open university education}

Reviewing the original beginning of the emergence of Open university education in New Valley reveals that the Construction Insititute offered an old building to be the nucleus of the center of the Open Education. This resulted in the problem of lack of healthy environment of learning (lighting, ventilation, toilets, classrooms, seats, and Cafeterias), as well as the lack of places for students to practice univerity activities and deactivitaing of students' unions and all other academic, scietific, literal and practical activities.

Perhaps all of this will be reflected negatively on their education, especially that most of the students come from official working or from other centers of the province, which lies hundreds of kilometers, they need food, water, air and climate and a healthy environment in the college.

In addition, the lack of an independent budget for the two branches of Open university education in New Valley which led to poor technical preparations in classrooms, lack of modern equipments and lack of electronic visual and audio liberary. It also led to lack of interaction among students and technical crew and lack of direct live meetings with the academic supervisors.

The nature of the geographical location of the province of New Valley, which is within a thousand kilometers from Cairo University and a distance of $300 \mathrm{~km}$ from Assiut University has resulted in a gap between the university administration and students. The features of this gap is represented in Novice students' lack of knowledge of university regulations, rights an obligations and also lack of training on using electronic programs and downloading courses at home.

The geographical location of New Valley also prevented many students from attending open classrooms due to their economic conditions or the distance between the place of residence from the center of Kharga, all of which led to underachievement and low level of graduates. It also led to late arrival of textbooks from Cairo University, and students' deprivation of some services and advatages available for graduates of other faculties. lack of sense of the academic atmosphere and the consequent low level of motivation among students towards learning.

Gf nf ngn yh It grew more difficult to open education in New Valley when the hired building was used as alocation of Agriculture and Veterinary Medicine faculties and consequently, Cairo and Assiut Univeristies were obliged to sign a protocol with New Valley faculty of education to hire an office for Open Education to compete the procedures of enrollement of students in its programs.(New Valley faculty of education .2013)

It should be noted that this new situation may force students to a range of problems, including:

1- The favortism in dealing with students by colleage's officers.

2- Low perception by students of the Faculty of Education to open education students in the belief that the level of open education is inferior compared to faculty of education.

3- The lack of independent organizational structure for open education programs and its dependence on the administrative system at the Faculty of Education.

4- The lack of activities of university as it is not indicated in the signed protocol.

This also led to the inability of New Valley faculty of education to meet the requirements of conducting the final examinations of Open Education in coincidence with final examinations of postgraduete studeis because of shortage in numbers of classes, chairs and tables.

In addition to all the previous problems there are other problems can be identified in the following points:

1- the hesitation of parents, and students who wish to enroll in university education between applying for admission and rejection because of the doubts on the credibility of the granted university degrees, the extent of acceptance of the appointment of Jobs, the extent of its equality to other certificates awarded by the Egyptian universities through direct or indirect affiliation or regular education and finally lack of practical lessons in most courses.

2- The shortage of programs of preparing, qualifying and following the officials of registration and training them on principles and basics of academic advising. 
3- The absence of supervision of the main center as the Open Education unit was managed by officials of the local government of Elkharga city.

4- The unsuitability of some basic courses in some collages like the collage of agriculture to the fiels of development in the governerate.

5- Most categories of students come from working class or return to school after a break, which poses a difficulty in achievement them and the combination of function, study and educational excellence.

6- The suffering of getting the certificate from Cairo and Assiut.

7- poor cooperation with the students by the management of the main center of the open education with regard to the postponement of the study or to apologize.

8- The centeralization of the adminstration of Open Education and lack of delegation of authority.

9- The irregularity of attending meetings in time especially professors of faculty of law and faculty of commerce in Assiut University.

10- The far distance between the center of study in Elkharga city and other places of students' residence.

11- Te shortage of a specialized liberary that may offer scientific references and resoueces.

12- Lack of a specific plan at the beginning of each semester for novice students' needs of training on open education learning techniques as well as the follow-up plan and evaluation.

13- Poor level of services at the building of faculty of education as the day of study for students of Open Education is Saturday; it is the second in the weekend for the College of Education.

14- Late arrival of textbooks from Cairo and Assiut.

15- The continous rise of expenses of travelling to the center of open education in Elkharga from different villages.

\subsection{The suggested prospective}

Review and analysis of Open Education problems in New Valley reveal that there are plurality and diversity among these problems; some problems associated to building, staff members, courses, exams, services, and needs of students. Therefore, the researcher suggests founding a center of Open Education in New Valley to use some mechanisms to solve these problems. The features of this center are suggested as follows:

\section{The Site of the Suggested Center:}

Due to the transmission of The collages of agriculture and veterinary medicine to the new site of the university; so it is suggested to replace them with the suggested center because it is a prime location and has services like cafeteria, restaurant, copy office, classrooms, computer- assisted laboratories and internet. The site is located in the center of Elkharga city just 200 meters far from faculty of education and surrounded by all services that meet needs of students.

\section{The Subordination of the Suggested Center:}

The suggested center follows Assiut University New Valley branch and is represented in the university council. This representation of the center manager guarantees that the university staff members will teach in the center. It should be noted here that the current protocol between faculty of education and Cairo University should be ended so that all Open Education programs are offered by Assiut University only in order to solve the above-mentioned problems.

\section{The Vision of the Suggested Center:}

The center aspires to be a beacon of cultural, civilizational and educational radiation by offering the opportunity of continuous education in the fields desired by students and in line with the requirements of development in New Valley's community.

\section{The Message of the Suggested Center}

The center is to apply quality system throughout its educational programs and services which aim to prepare students who desire to continue their education scientifically and practically according to the needs of the society in New Valley.

\section{The Aims of the Suggested Center:}

a) Offering continuous education for those who want to raise their scientific and cultural level according to their needs, abilities and resources.

b) Offering university certificate for those who were deprived from completing their education among the graduates of high school or any equivalent certificate.

c) Offering knowledge and study in varied fields for owners of different specializations.

d) Offering scientific experience for those who work in different sectors and fields.

e) Achieving the principle of relating Open university education to the society of New Valley.

f) Using new programs and leaning techniques that suit labour market in New Valley.

\section{Principles of Founding the Suggested Center:}


a) Using new educational techniques based on high technology.

b) Offering education for people regardless their different social, economic, spatial and periodical conditions.

c) Creating direct connection between the center of open education and local society institutions.

d) Relating the programs and courses of open education center to the educational needs of the society.

e) Participating in raising the cultural, scientific and social level of people.

7. Rules of Admission in the Suggested Center:

a) Coordination with information center of the governorate to specify the disciplines needed of labor market and then specifying number of admitted students of intermediate and above intermediate certificates.

b) Raising the minimum grade of acceptance of high school students to $60 \%$.

c) Application of personal interview of the admitted students to specify their desires in education.

d) Cancelling the conditions that may eliminate number of accepted students like completing 5 years after last graduation.

\section{Technical and Administrative Support Teamwork:}

The members of the teamwork should be assigned according to the the different needed specializations to fulfill the technical and administrative work of students' registration in courses and programs, copying and distributing materials and textbooks, protecting copyrights, writing reports and conducting technical resources.

\section{Registration System in the Center}

It should be taken into account that the academic supervisors should be allocated among staff members to help students register in educational courses, hold continuous interviews to solve their problems, and develop a specific plan for novice students' training needs on Open Education strategies at the beginning of each semester. These supervisors should also be trained to know the most important modern trends of Open Education and guiding students.

\section{Facilities and Technical Equipment in the Suggested Center:}

a) Designing a website of the suggested center.

b) Founding computer labs connected to the internet and equipped with e-boards for distant learning. Labs of faculty of education can be used at the beginning.

c) Providing programs of assessment and evaluation at these labs to conduct testing as near as possible.

d) Providing self-learning resources like libraries, computers and internet.

e) Transforming courses and lectures into electronic materials.

f) Uploading the electronic lectures on the website of the center.

11. Curricula and Courses of the Suggested Center:

New courses and programs should be adopted and consistent with the environment of New Valley and help to be engaged in labor market and new professions and disciplines. There is also a need to increase hours of practical exercises, field visits and formation of Committees to evaluate the academic content and develop it every 4 years. It also must here take into account the use of radio broadcasting in the process of delivering lectures to students in different centers of the governorate, and continue to re- broadcast lectures because of the far distance of the Centers of Eldakhla, Farafra, Paris and Balat from the center of Kharga. educational media in specific places should be provided and declared for students residing in all centers, even students can borrow them and return them.

\section{Suggestions for Students of the Suggested Center:}

a) Holding training workshops for novice students at the beginning of each semester to acquaint them with registration system, selecting courses, using website and different resources of knowledge.

b) Offering incentives for distinguished students in form of scholarships, money or incorporeal awards.

c) Consulting students when making important decisions related to their studies such as the decision of retesting the study subjects of two parts when failing in either part.

d) Designing students' activities like students' union and e-activities to introduce their ideas and suggestions theoretically and practically..

e) Exempting, wives, husbands, sisters, brothers, half-brothers and excellent students of tuition fees partially or completely.

\section{Staff Members of the Suggested Center:}

It is suggested to depute completely or internally staff members from Assiut University or research centers of the governorate because of the far distance between New Valley and Assiut. When that seems difficult, the center can appoint new staff members from New Valley's citizens and the priority should be given to those obtained master and doctorate degrees. The following should be considered among the appointed: understanding and study of the needs of students, using suitable teaching techniques and strategies that take into account the needs and diverse expectations of students, dealing with communication technology, working effectively as a guide and a monitor of academic content and 
developing evaluation plans objectively and electronically.

\section{Administration of the Suggested Center:}

The members of administration council are elected and include some honorary members of businessmen, some leaders of governorate, a female student and a male student elected by their colleagues. The administration council is responsible of arranging the work by applying decentralization, revising internal law of Open Education and paying financial allocations of students' tuition fees in supporting the center and its activities.

\section{Evaluation of Students of the Suggested Center:}

Evaluation process should be continuous throughout the year by discussions, researches and practical applications to guarantee the commitment of students and prevent their absence. In addition, mid-term tests should be applied and deserve $20 \%$ of the total grade while the other $30 \%$ of practical test and $50 \%$ for the theoretical written tests. Tests also are conducted asynchronously with faculty of education's tests to benefit the staff in conducting tests. The circumstances of students who work in different governmental institutions students should be put into consideration.

\section{Certificates Offered by the Suggested Center:}

The center offer certificates in (Technology and administration of agriculture projects- economy and interior commerce- desert science- tourism and archeology studies- English language). These certificated are to be offered with estimation scoring.

\section{Funding the Suggested Center:}

The center may be funded by the tuition fees of registration of students, grants of businessmen, establishment of a suggested fun for financial support of poor students, local society institutions' participation in supporting Open Education by offering money or equipment and encouraging the organizations of civil community to pay for their officials' Open Education and and installment the money.

\section{Conclusion}

The educationalists and responsible leaders of education began to think in varied alternatives and different solutions to solve the problem of high education's disability to offer places for thousands of high school graduates. Open Education and distant education are types of these new educational solutions.

The philosophy of Open Education is to spread education in general and high education in particular as the latter is a flexible system that offers education for all according to their circumstances without any limits of age, internationality, certificate or year of graduation.

Some faculties of Open Education centers of Assiut and Cairo universities were established in New Valley- in the eastern south of Egypt- like faculties of commerce, law, information, agriculture, and science.

Analyzing the reality of Open Education in New Valley resulted in identifying some problems; some of them are related to the current location of Open Education and the other problems are related to administrative services, staff members, administration, courses, missing the meetings and classes and students' absence because of their economic circumstances and distant residence from Kharga.

As a result of these circumstances, the researcher proposed a suggested view of Open Education center in New Valley to solve the problem of the current reality and attempet to develop it.

\section{Recommendations of the Study}

1- Supporting the suggested center by Assiut University council, completing the procedures of its approval and providing the necessary resources.

2- The coordination between Assiut University and New Valley governorate to form a specialized committee in order to specify the needed specializations and programs which meet the requirements of development in New Valley.

3- Designing activities and programs to motivate citizens to join the suggested center.

4- Immediate actions of announcing jobs of the staff members according to the needed specializations in the suggested center by full secondment or announcement of jobs.

5- Benefiting distant education technology in teaching and training officials in developmental projects in New Valley.

6- Acquainting novice students with professions that New Valley needs, the shortage and increase of these professions, the skills and abilities needed by individuals, and programs that qualify them professionally.

7- Coordinating with services and production sites in New Valley to train students productively in vocations. 
Students should not graduate unless they practice what they learn in these sites.

8- Conducting follow-up studies for the graduates of different programs of the suggested center through retraining them after graduation in order to update their knowledge and new skills needed by the work market.

9- Continuous review of Open Education system of the suggested center to achieve harmony with changes of New Valley's society.

\section{References}

Mustafa, H. (2011): social backwardness: the entrance to the oppressed human psychology. the Arab Cultural Center, Cairo, 1-2.

Saied, A. and Seraj, Y., (2006): "Challenges for Integrating Teaching and Research with Community Services: A View From Developing Countries". 4th. International Forum on Engineering Education, IFEE2005, Integrating Teaching and Research with Community Service, University of Sharjah, Sharjah.

Khalion,B. (1998):The Arab World and the 21st. Challenges. Arab Future Magazine, 232:22-24.

Kamil, C. and Oznur, O.(2012) : Bologna Process and Anadolu University Open Education System . International Educational technology Conference, Procedia - Social and Behavioral Sciences, $64: 275$ - 283.

Jacob, N. (2004) : distance education and Open University education. Dar-Furqan, Jordan .

Nashwan, Y. (2004). Distant education and High Open Education. Dar Elforkan, Jordan.

Fathy M. \& Mohammed S. (2010). Assessing the quality of high Open Education in Egypt according to the providers and benefiters' view. The Arabic journal of quality assurance of high education, $5: 3$.

Elakaad L.(2001): Open Education via networks. Mawoshi Press, Lebanon.

New Valley governorate. (2012): A study of the areas available to accommodate the surplus of graduates in the New Valley, Center for Information and Decision Support. Elkharga, p.15.

Demiray (1999).Faculty of Open Education Graduates' Relations with Working Life Eskisehir, online: http://www.tojet.net/e-book .

Shaheen M.A. (2005). Motives and obstacles of using the internet by the officials in Elquds Open University Journal, 6: 89-128.

Hamaiel A.A \& Hamaiel M.A. (2006). the obstacles face by academic supervisors in Elquds Open University during use of the university academic website. Elquds Open University, Elquds Open University Journal for studies and research,8 : 11-68

Abo Samra et al (2006). the obstacles face by academic supervisors in Elquds Open University in Palestine,Elquds Open University, Journal for Studies and Research, 8: 69-110

Yakoub, H. (2001). preparing and training officials in distant and Open Education. Distant and Open Education. Arabic organization of education, culture and science. Arabic workshop of distant and Open Education. Tunsia, 31 July- 3 August.

Abdelrahman, M. (2000). the experience of Open Education in Egypt, an evaluative study of the experience of Open Education in faculty of commerce Cairo University. M.A. Faculty of Education, Tanta University.

Ehazab, A. (2001). Educational efficiency of Open Education center of Cairo University. M.A. Faculty of Girls, Ain Shams University.

Metwally, S. (2004). Quality of Open Education program in Faculty of Commerce Cairo University in light of global trends. PhD. Education Studies Institute, Cairo University.

Elsaidi, A. (2005). The Reality of open education in faculty of law and its problems. The conference of information and competitive ability of Open Education: Arabic developmental prospectives. Sama Village international, Elarish, Open Education Center Of Ain Shams University.

Sadia A. and Mostafa A. (2002). Distance Education and Open Learning in a Developing Country like Bangladesh: Philosophy and Reality. Bangladesh Open University.

Michael, A. and Rodrigo, B.(2008). Open Education and Education for Openness. Educational Future Rethinking Theory and Practice, Sense Publishers, P.27.

Keegan, D. (1986). The foundation of distance education. London, Croom Helm. Available at: http://www.wikipedia.org.

Christelle, S.,(2013). An assessment of work-integrated learning for public relations in an Open distance Learning context . Public Relations Review , Elsevier ,P. 2

Simonson, M. and et. al, (2000): Teaching and learning at a distance: Foundations of distance education. Upper Saddle River, NJ: Merrill (Prentice - Hall).

Chute, A. and et. al , (1999): The McGraw-Hill handbook of distance learning. New York: McGraw-Hill, P.220.

Alkan, C. (1996). The Historical Development of Distance Education. Turkey International Distance Education Symposym, Ankara.

Kanwar, A. and Daniel, J. (2010): Distance Education and Open Universities. Commonwealth of Learning, Vancouver, BC, Canada, Elsevier Ltd. All rights reserved, P.405.

Lockwood, F. (1995). Open and distance learning today. London: Rutledge.

Neil B.,(2011):A Basic Guide to Open Educational Resources (OER) , Commonwealth of Learning , UNESCO ,P.6.

Suez Canal University, Faculty of Environmental Agricultural Science in Alarish, Open Education center, The interior Law of Agriculture Education, P.2.

Abd Elmotelib, A. (2006). Research and Studies in Education, 1st part. Sohag,:158-164.

Bedewi, R. M. (2008). The role of Open Education in satisfying the needs of local development in Sinai (Field study), Faculty of Education Journal, 60: 86-89

New Valley faculty of Education: The Internal annual report of (2012-2013).43 